\title{
LA ENSEÑANZA DE TÚ, VOS Y USTED A TRAVÉS DE CANCIONES: UNA PROPUESTA SOCIOLINGÜÍSTICA
}

\author{
Valdecy de Oliveira Pontes \\ Livya Lea de Oliveira Pereira \\ Leandra Cristina de Oliveira
}

\begin{abstract}
RESUMO
Apresentamos neste trabalho uma proposta didática para o ensino dos pronomes castelhanos túlvos/usted, com base em cançôes de diferentes regióes hispano-falantes. Nosso debate, que se volta para o âmbito pedagógico, fundamenta-se em pressupostos teóricos da Sociolinguística laboviana, bem como em documentos oficiais voltados para o ensino.
\end{abstract}

PALAVRAS-CHAVE: variação e mudança linguísticas; pronomes de tratamento; ensino.

\section{Consideraciones iniciales}

n Brasil, la aprobación de la Ley 11.161 sugiere el aumento del interés por el aprendizaje de la lengua española. Sin embargo, aún enfrentamos obstáculos en la enseñanza de este idioma en ámbito nacional, pues, como señala Ayala (2004, p. 27) hay un insuficiente número de profesorado cualificado, poca carga horaria y escasez de material didáctico. Sumado a estos factores, encontramos la problemática planteada por autores como Buguel (1998), Kraviski (2007) y Pontes (2009) sobre la extensa publicación de materiales de lengua española en contexto extranjero, con poca atención a las variedades hispánicas. De esta realidad, emergen preguntas clásicas en el ámbito del español como lengua extranjera: ¿qué español aprendemos?, ¿los 
materiales didácticos consiguen abordar las muchas voces hispánicas?

Las Orientaciones Curriculares Nacionales para la Enseñanza Media (OCN/EM, 2006) y los Parámetros Curriculares Nacionales para la Enseñanza Media (PCN/EM, 2000) mencionan la importancia de la enseñanza de lengua considerando el conocimiento de la variación lingüística, principalmente en lo que atañe al combate de estereotipos y/o prejuicios. Asimismo, fomentando la búsqueda de recursos didácticos que contribuyan a la enseñanza de lengua desde una perspectiva de la variación lingüística, proponemos el uso de canciones para elaboración de actividades que posibiliten el conocimiento de casos de variación en las formas de tratamiento, ya que, según Carricaburo (1997, p. 11) y Calderón Campos (2010, p. 226), hay una infinidad de tipos de voseo, tuteo y ustedeo en el mundo hispánico. ${ }^{1}$ Además, las canciones representan objetos de aprendizaje auténticos, y con ellas se pueden abordar los diversos niveles lingüísticos y temas culturales, así como posibilitar la práctica de distintas habilidades lingüísticas.

De esta forma, con el objetivo de asociar discusiones teóricas a la práctica docente, presentamos en este artículo una propuesta de actividad que plantea el contraste entre los pronombres de tratamiento TÚ, VOS y USTED en Colombia y Puerto Rico, a través de la canción "Falsas Palabras", del cantante colombiano Juanes, y de la canción "Soy igual que tú", del dúo puertorriqueño Alexis y Fido, a título de ilustración. Esta propuesta de actividad - presentada de forma extendida en Pereira (2014, p. 46 - 50) - se basó en orientaciones sociolingüísticas presentes en documentos oficiales de la enseñanza brasileña, como las OCN/EM (BRASIL, 2006) y los PCN/EM, (BRASIL, 2000), además de las contribuciones teóricas de Moreno Fernández (2000, 2010), Buguel (1998), Kraviski (2007), Pontes (2009), entre otros.

\section{Las orientaciones sociolingüísticas}

Con el desarrollo de la Sociolingüística, la visión de lengua como algo estático y homogéneo ha sido contestada en favor de una concepción de lengua

1 Según Calderón Campos (2010, p. 233), se puede entender el ustedeo como el uso del usted en situaciones de confianza o intimidad. Por tuteo, se puede comprender el uso del tú y su paradigma pronominal y verbal para tratar a un interlocutor. Y, por voseo, se entiende el uso del vos o de las formas verbales de la $2^{\underline{a}}$ persona del plural para dirigirse a un interlocutor en singular, en situaciones de solidaridad, confianza o intimidad. 
que pone en evidencia la heterogeneidad lingüística. Según Mollica (2003, p. 11), esta área de la Lingüística considera que las lenguas poseen un dinamismo inherente, lo que resulta considerarlas heterogéneas. Así que se estudia la lengua en su contexto social de uso, teniendo en cuenta aspectos lingüísticos y sociales. Además, considera como uno de sus fenómenos de estudio la variación lingüística, la cual, según Labov (1978), se refiere a los modos alternativos de decir la misma cosa, es decir, de indicar el mismo significado referente.

La variación lingüística puede ocurrir en los diversos niveles de la lengua, tales como: fonológico, sintáctico, morfológico y lexical. Asimismo, Tarallo (2005, p. 08) clasifica las variaciones en: diatópicas (diferencias relacionadas a los espacios geográficos), diastrásticas (diferencias relacionadas a aspectos sociales, como clase social, sexo, edad etc.) y diafásicas (diferencias relacionadas al contexto de comunicación y estilos del lenguaje). Además, podemos citar otras dos categorías de variación: la diamésica, (diferencia relacionada a la modalidad oral o escrita de la lengua) y la diacrónica (relacionada al momento histórico de la lengua y su evolución). En cuanto a la actividad propuesta en este trabajo, el tratamiento de la variación entre tú, vos y usted considera factores relacionados a las diferencias diatópica y diastrástica.

Respecto a la importancia del estudio bajo la perspectiva de la sociolingüistica variacionista es notable la comprensión de la lengua a partir de su función comunicativa y social, la cual identifica grupos y demarca diferencias sociales (COAN; PONTES, 2013). También, con el estudio de la variación se puede combatir la propagación de prejuicios lingüísticos, a partir de la promoción de la "norma social" y de relativización de la noción de "error".

Importa destacar que, en este trabajo, el término "norma social" es asumido a partir del estudio de Matos y Silva (1995, p. 72), que menciona la posibilidad de diferentes normas: normas literarias, normas sociales, normas regionales etc. En este sentido, el término "norma" nada tiene que ver con la convencionalizada "norma gramatical". A partir de esta mirada, es coherente estudiar y comprender la lengua en uso - la "norma social" -, a veces no reconocida por la escuela como expresión lingüística natural y legítima, de acuerdo con lo que menciona Mollica (2003, p. 14). Asimismo, estudiar la lengua bajo la perspectiva sociolingüística, asumida en esta propuesta, puede concienciar al alumno que la lengua no se resume a lo que presentan las gramáticas y manuales didácticos. 
Para esta discusión direccionada a la pedagogía de la lengua, cabe citar documentos oficiales elaborados por el Ministerio de Educación de Brasil para auxiliar a los profesores en sus planteamientos, como las OCN/EM (BRASIL, 2006) y los PCN/EM (BRASIL, 2000). Analizamos estos documentos de modo a verificar la posible contribución de la teoría sociolingüística para el ámbito pedagógico. Tras este examen, organizamos en el cuadro a continuación una síntesis de los razonamientos sociolingüísticos encontrados en las $\mathrm{OCN} / \mathrm{EM}$ y los PCN/EM ${ }^{2}$ y también de algunos autores que consideramos en la elaboración de la actividad expuesta en este artículo.

Cuadro 1. Orientaciones sociolingüísticas para la elaboración de actividades

\begin{tabular}{|c|c|}
\hline $\begin{array}{l}\text { O C N / E M } \\
(2006)\end{array}$ & $\begin{array}{l}\text { - "Considerar la heterogeneidad lingüística y cultural del mundo } \\
\text { hispánico en la enseñanza del español y estimular esa reflexión." } \\
\text { - "Exponer los estudiantes a las variedades sin reproducir } \\
\text { dicotomías simplistas y reductoras, tampoco propagar prejuicios } \\
\text { lingüísticos." } \\
\text { - "El profesor tiene libertad para elegir la variedad que más le } \\
\text { agrade, sin embargo, eso no le impide aproximar a los alumnos } \\
\text { de las otras variedades, incluso, derribar estereotipos o prejuicios." } \\
\text { - "Abordar la variedad desde los niveles iniciales, creando } \\
\text { oportunidades de conocimiento de las otras variantes, además de } \\
\text { la que utiliza el profesor o el libro didáctico." }\end{array}$ \\
\hline $\begin{array}{l}\text { P C N / E M } \\
(2000)\end{array}$ & $\begin{array}{l}\text { - Saber distinguir entre las variantes lingüísticas. } \\
\text { - Escoger el registro adecuado a la situación en la que se procesa } \\
\text { la comunicación. } \\
\text { - Comprender de qué forma determinada expresión puede in- } \\
\text { terpretarse en razón de aspectos sociales y/o culturales. }\end{array}$ \\
\hline
\end{tabular}

2 Traducciones de nuestra responsabilidad. 


\begin{tabular}{|c|c|}
\hline $\begin{array}{l}\text { OTROS } \\
\text { ESTUDIOS }\end{array}$ & $\begin{array}{l}\text { - "Estudiar la variación lingüística ayuda a destruir prejuicios } \\
\text { lingüísticos y relativizar la noción de error" (MOLLICA, 2003, } \\
\text { p. 13). } \\
\text { - "La norma culta del español para la enseñanza, no es única, sino } \\
\text { múltiple." } \\
\text { "No hay ninguna comunidad de habla en la que los hablantes de } \\
\text { prestigio lingüístico deban servir de único modelo para todo el } \\
\text { mundo hispánico." (MORENO FERNÁNDEZ, 2000, p. 77). } \\
\text { "Las variantes lingüísticas traspasan la labor docente, desde la } \\
\text { selección de los materiales didácticos, hasta la manera de afrontar } \\
\text { las dudas sobre los usos lingüísticos." (MORENO FERNÁNDEZ, } \\
\text { 2010, p. 47). } \\
\text { - "La lengua es parte de la cultura y de la personalidad de los } \\
\text { hablantes." (BUGUEL, 1998, p. 192). } \\
\text { "No es adecuado abandonar una variedad en favor de la que } \\
\text { presenta los materiales didácticos, o intentar abarcar todas las } \\
\text { variantes lingüísticas del español, pues resultaría lejano de la } \\
\text { realidad lingüística." (BUGUEL, 1998, p. 192). } \\
\text { - "El profesor debe concientizar a los alumnos sobre la diversidad } \\
\text { cultural, pues también es un formador de ideologías" (KRAVISKI, } \\
\text { 2007, p. 72). } \\
\text { "El componente cultural debe abarcar la presentación de las } \\
\text { variantes lingüísticas a los alumnos de lengua española a fin de } \\
\text { evitar prejuicios lingüísticos." (KRAVISKI, 2007, p. 74). } \\
\text { - "Es necesario mostrar las diferencias, tanto las lingüísticas, como } \\
\text { las culturales, y encontrar el lugar de las semejanzas; además de } \\
\text { contribuir con una relación más profunda con los universos en los } \\
\text { cuales los alumnos están penetrando, de aceptar más la diferencia } \\
\text { como enriquecedora." (SANTOS, 2002, fuente electrónica). } \\
\text { - "El profesor en la enseñanza de lenguas debe traspasar los límites } \\
\text { de la norma estándar de la lengua." (PONTES, 2009, p. 22). }\end{array}$ \\
\hline
\end{tabular}

\section{Materiales didácticos y uso de canciones en la enseñanza del español}

Según Geraldi (1991, p. 32) el libro didáctico, al disminuir la responsabilidad por la selección de contenidos de enseñanza y elaboración de actividades, facilitó el trabajo del profesor, pero contribuyó a la dependencia y al uso casi exclusivo de este recurso. Sobre esta cuestión, es importante reconocer 
las deficiencias de este material, así que es sustancial la reflexión crítica de su principal usuario: el profesor.

En los libros didácticos, el tratamiento de la variación lingüística puede ser muy reducido o superficial, como señala Pontes (2009) al analizar algunos libros didácticos del portugués y del español utilizados en la enseñanza brasileña. Otras investigaciones corroboran el tratamiento desigual de las variedades lingüísticas en los libros didácticos de español, como Buguel (1998), Kraviski (2007) y Nascimento (2007). Importa advertir que, si el libro no lleva en consideración la realidad heterogénea de la lengua, es posible conjeturar la presentación exclusiva de determinada variedad, presentándola como homogénea o superior. Respecto a eso, son imprescindibles la atención y la visión crítica del profesor frente a las ideologías explícitas o implícitas en los materiales didácticos.

Asimismo, si el libro didáctico que se utiliza no es suficiente para enseñar la existencia de la variación lingüística, el profesor puede buscar otros recursos, tales como videos y canciones, cuyo uso en clases de lengua extranjera es, actualmente, relativamente simple.

Ferreira (2012, p. 17) señala que muchos profesores utilizan las canciones con sus alumnos en distintas asignaturas, con diferentes objetivos - desde la fijación de contenidos hasta la realización de actividades lúdicas. Este autor defiende que, a través de la música, es posible despertar y desarrollar en los alumnos la sensibilidad y la atención frente a cuestiones propias de la asignatura meta.

Ledezma (2007, p. 17) presenta algunas ventajas con el uso de músicas en la enseñanza de español, las cuales son: posibilitar el trabajo con los diferentes niveles de la lengua; estimular las cuatro destrezas lingüísticas; ejemplificar diferentes estilos literarios; representar textos auténticos; posibilitar la expresión de emociones y reacciones individuales; estimular el juego y la creatividad; estimular la memoria; presentarse como un elemento motivador y una herramienta útil para la enseñanza de contenidos culturales, históricos y sociales.

Santos Asensi (1996, p. 367) afirma que las canciones ofrecen múltiples posibilidades de integración de temas de la actualidad cultural e incluso de contenidos de otras áreas curriculares. Para este autor, la facilidad de grabarlas en la memoria, por su aspecto pegadizo, es uno de los principales argumentos en defensa del potencial didáctico de este recurso.

En esta perspectiva, Silva (2007, p. 14) señala que con la música se pueden abordar las diferencias y variaciones lingüísticas, por caracterizarse 
como un género de amplia circulación social, en el cual formas variantes se manifiestan. No obstante, al utilizar músicas como muestras lingüísticas en clase hay que señalar que el lenguaje de las canciones poseen algunas características particulares, como alude Santos Asensi (1996, p. 368), tales como: la predominancia de las formas de tratamiento de primera y segunda personas; pocas referencias a situaciones concretas de tiempo y lugar; uso frecuente de imperativos, apelativos, exclamaciones y preguntas directas; oraciones y frases cortas o incompletas; el amor como temática predominante, uso de registros poéticos, coloquiales o vulgares; uso de palabras y expresiones que desarrollan con facilidad sensaciones, sentimientos o ideales; uso de metáforas, rima, repetición de palabras, entre otros. Lo que puede influir en los usos lingüísticos presentes en la canción.

Para la selección de las músicas utilizadas en la actividad presentada en este artículo nos basamos en la división de la lengua española en zonas lingüísticas, propuestas por Moreno Fernández (2000, p. 23 - 28; 2010, p. $72,75,77,89-102)$, a fin de elegir y contrastar variedades de países de distintas zonas lingüísticas. ${ }^{3}$ Luego, nos basamos en los siguientes criterios al elegir las canciones: (i) actualidad de la temática; (ii) zona lingüística; (iii) presencia de las formas de tratamiento de segunda persona singular; (iv) representatividad del cantante en la comunidad de habla que figura; (v) extensión de las canciones; y (vi) disponibilidad o accesibilidad en internet. Asimismo, con el auxilio de sitios electrónicos, como musicstarx.com (para acceder a ranking musicales de los países), kboing.com.br y letras.mus.br (para ver y oír las letras de las canciones), entre otros sitios, elegimos las dos canciones que componen la actividad aquí ilustrada. Por último, las analizamos según aspectos lingüísticos (presencia de las formas de tratamiento, usos y valores y paradigma verbal) y extralingüísticos (zonas lingüísticas, ritmo, temáticas, cantantes y/o intérpretes).

3 Moreno Fernández (2000, 2010), fundamentando en estudios dialectológicos clásicos, divide la lengua española en zonas lingüísticas según los usos de ciudades y territorios más influyentes. Las zonas discutidas en los referidos estudios son: 1. El Caribe (Cuba, República Dominicana, Puerto Rico y Venezuela); 2. México y América Central (México, Guatemala, El Salvador, Honduras, Nicaragua, Costa Rica y Panamá); 3. Los Andes (Colombia, Ecuador, Perú y Bolivia); 4. Río de La Plata (Argentina, Paraguay y Uruguay); 5. Chile (Chile); y 6. España (Región Castellana, Andaluza y Canarias). 


\section{Propuesta de actividad: contraste entre tú, vos y usted}

La coexistencia de los pronombres de tratamiento tú, vos y usted en una misma comunidad de habla se convierte en un sistema difícil de describir (CALDERÓN CAMPOS, 2010, p. 230), ya que factores como la región geográfica, la capa social, la edad, el sexo, entre otros, pueden influir en la elección de una de las formas. De este modo, para contrastar los usos y valores de estas formas de tratamiento, seleccionamos canciones de Colombia y Puerto Rico, países de zonas lingüísticas distintas en los que coexiste más de una forma de tratamiento en singular.

En algunas partes de Colombia, las formas vos y tú coexisten en el habla popular para tratamiento de confianza e intimidad, mientras en las clases más elevadas se prefiere el tuteo. También, en este país, se verifica el ustedeo - fenómeno determinado por el sexo. Calderón Campos (2010, p. 230) señala, además, que en la región voseante, desde la región pacífica hasta el río Cauca (principalmente, Antioquia y Medellín), hay frecuente alternancia vos/túlusted en el mismo acto comunicativo y con el mismo interlocutor.

Ya en Puerto Rico, según Carricaburo (1997, p. 11), se verifica un tuteo extendido socialmente, incluso en situaciones donde se utilizaría el usted. En este país, factores sexistas influyen en la elección entre tú y usted: los hombres tienden a tutear a las mujeres más que a otros hombres, y las mujeres se tutean entre sí. También se utiliza el usted en ciertos contextos: con interlocutores mayores, de más autoridad, con desconocidos, y en situaciones de enfado, según Calderón Campos (2010, p. 234).

En atención a estos usos heterogéneos, para la actividad propuesta, traemos la canción "Falsas Palabras" ${ }^{4}$ del cantante colombiano Juanes, nascido en Medellín. En la referida canción, se verifica una temática de desilusión amorosa, en la cual se expresa rabia y rencor. La segunda canción utilizada es "Soy igual que tú”, del dúo puertorriqueño Alexis y Fido, en la que también se observa como tema principal una desilusión amorosa y la traición. La primera canción es un pop rock latino, un ritmo que quizá sea más conocido por los aprendientes; la segunda, por otro lado, posee un ritmo típico de Puerto Rico, el reggaetón.

4 Las músicas utilizadas en la actividad, "Falsas Palabras" y "Soy igual que tú", se encuentran disponibles, respectivamente, en los sitios electrónicos: <www.letras.mus.br/juanes/1356245/> y <http://letras.mus.br/alexis-y-fido/1129283/>. 
A continuación, presentamos la propuesta de actividad, la cual puede ser modificada/adaptada según el nivel del grupo, objetivos del programa y carga horaria disponibles por el profesor:

Cuadro 2. Propuesta de Actividad (Contraste entre tú, vos y usted)

\begin{tabular}{|c|c|}
\hline Nivel & $2^{\circ}$ año de la secundaria \\
\hline Tiempo & 50 minutos. \\
\hline $\begin{array}{l}\text { O r i e n t a c i ó n } \\
\text { sociolingüística }\end{array}$ & $\begin{array}{l}\text { 1. Aproximar a los alumnos de diferentes variedades lingüísti- } \\
\text { cas, incluso, derribar estereotipos o prejuicios (BRASIL, 2006). } \\
\text { 2. Escoger el registro adecuado a la situación en la que se } \\
\text { procesa la comunicación (BRASIL, 2000). }\end{array}$ \\
\hline Zona lingüística & $\begin{array}{l}\text { Zona de Los Andes (Colombia) y Zona del Caribe (Puerto } \\
\text { Rico). }\end{array}$ \\
\hline Variación & $\begin{array}{l}\text { Diatópica y diastrástica de los pronombres de tratamiento tú, } \\
\text { vos y usted. }\end{array}$ \\
\hline $\begin{array}{l}\text { Descripción de } \\
\text { la actividad }\end{array}$ & $\begin{array}{l}\text { 1. Poner en la pizarra el nombre de los países en análisis: } \\
\text { Colombia y Puerto Rico. } \\
\text { 2. Preguntar a los alumnos qué saben sobre esos países, qué } \\
\text { artistas colombianos o puertorriqueńos conocen. } \\
\text { 3. Pasar el videoclip de las músicas "Falsas palabras" (http:// } \\
\text { www.youtube.com/watch?v=16BevTjNVLI) "Soy igual que } \\
\text { tú" (http://www.youtube.com/watch?v=CHC6_9j72ro) y } \\
\text { pedirles que los relacionen a los países de origen. } \\
\text { 4. Entregar la letra de las canciones para los alumnos y } \\
\text { solicitarles que las lean buscando identificar el tema y el } \\
\text { interlocutor, luego hacer una puesta en común. } \\
\text { 5. Pedirles que identifiquen y ejemplifiquen los pronombres } \\
\text { de tratamiento utilizados en ambas las canciones. } \\
\text { 6. Apuntar algunos ejemplos en la pizarra y razonar en grupo } \\
\text { sobre los diferentes usos de los pronombres, destacando la } \\
\text { diversidad de funciones en cada país. } \\
\text { 7. Para finalizar, el profesor puede pasar nuevamente la } \\
\text { canción colombiana, y preguntar a los alumnos si se podría } \\
\text { utilizar el mismo tratamiento al interlocutor, si la canción } \\
\text { fuera puertorriqueña y viceversa. }\end{array}$ \\
\hline
\end{tabular}




\begin{tabular}{|l|l|}
\hline \multirow{3}{*}{$\begin{array}{l}\text { Otras } \\
\text { sugerencias }\end{array}$} & $\begin{array}{l}\text { Para esta actividad, el profesor puede también ocultar los } \\
\text { pronombres de tratamiento en las dos canciones, para que los } \\
\text { alumnos intenten completarlas antes de escucharlas. Además, } \\
\text { si el grupo conoce poco o nada de Colombia y Puerto Rico, se } \\
\text { pueden proponer investigaciones extra-clase sobre las músicas } \\
\text { de esos países u otro tema cultural de interés de los estudiantes. } \\
\text { Conforme el tiempo destinado al curso y el perfil de los } \\
\text { estudiantes, bajo una perspectiva intercultural, es pertinente } \\
\text { asociar el tema a aspectos socioculturales, como: las relaciones } \\
\text { interpersonales en Brasil y en los países debatidos, diferencias } \\
\text { y semejanzas entre estas culturas en cuanto al uso de los } \\
\text { pronombres de tratamiento en relaciones íntimas, simétricas } \\
\text { y asimétricas, entre otras reflexiones. }\end{array}$ \\
\hline
\end{tabular}

En la primera parte de la actividad, el profesor verifica los conocimientos previos de los estudiantes acerca de la variedad lingüística y los aspectos socioculturales de Colombia y Puerto Rico, con atención a la existencia de estereotipos o prejuicios respecto a estos países. Al presentarles el video de las canciones y pedirles que las relacionen con los países, se llama la atención a la actividad, al mismo tiempo que se discute como aspecto cultural la diferencia de géneros musicales en Latinoamérica, señalando el rock latino de Juanes y el reggaetón del dúo Alexi y Fido. En esta parte de la actividad, se objetiva la concientización de la diversidad cultural, pues, como señala Kraviski (2007, p. 72), el profesor es un formador de ideologías y, por consiguiente, debe esforzarse para romper los estereotipos o prejuicios que existan por parte de los alumnos. Al proponer que identifiquen el tema y el interlocutor de las canciones, se objetiva que reconozcan el registro utilizado, asimismo, con la puesta en común, es necesario dejar claro que el tema principal es la desilusión amorosa y que los interlocutores se refieren a personas de intimidad o confianza. A partir de eso, se propone que los alumnos busquen las formas de tratamiento utilizadas en las canciones, con el fin de que perciban la variación diatópica y funcional de este fenómeno lingüístico bastante frecuente en las diversas situaciones comunicativas.

En lo concerniente a la forma de tratamiento utilizada en la canción "Falsas Palabras", encontramos el uso de los pronombres tú y vos, como se constata en los versos a continuación: 
1. "Si tú no me amas"

2. "Si tú no me quieres querer"

3. "Y por qué diablos me hablas así como si nada"

4. "Yo fui bueno con vos"

5. "Un amor como vos".

6. "No te das cuenta que ya no soy el tonto que solía ser"

7. "No valen tus palabras",

En los datos 1 y 2 , se verifica el pronombre tú de forma explícita, además de las marcas morfológicas en los verbos amar y querer, conjugados en segunda persona del singular. En el dato 3, se constata el tratamiento de segunda persona singular a partir de la morfología verbal marcada en "hablas". Ya en las ocurrencias 4 y 5 , encontramos el pronombre vos pospuesto a la preposición "con" y en expresión de comparación, respectivamente. Se conjetura que la alternancia de tú para vos, en estos casos, se justifica por la exigencia rítmica de la canción. También, en los versos 6 y 7 se verifica, respectivamente, la forma clítica "te" y el posesivo "tus", correspondientes tanto al tratamiento tuteante como voseante.

Importa destacar a los estudiantes que la alternancia entre tú y vos corrobora la relación de intimidad entre los participantes representados en la canción. De este modo, el profesor puede aprovecharse de este recurso lingüístico para discutir la variación presente en algunas regiones colombianas, como la representada por el cantante Juanes - Medellín -, respecto a la expresión de segunda persona del discurso.

De esta forma, para fomentar el razonamiento lingüístico de la alternancia túlvos en la canción, el profesor puede elegir algunos versos para apuntar en la pizarra y proponer a los estudiantes algunas reflexiones, tal como las que se ilustran en el cuadro a continuación. 
Cuadro 3. Datos y cuestiones para análisis didáctico

\begin{tabular}{|c|c|}
\hline Datos & Cuestiones para reflexión \\
\hline $\begin{array}{l}\text { 8. "Si tú no me amas, ¿para qué diablos } \\
\text { te voy a querer" } \\
\text { 9. "Yo no me merezco este dolor Yo fui } \\
\text { bueno con vos" }\end{array}$ & $\begin{array}{l}\text { ¿Quiénes son los participantes de la } \\
\text { interacción ilustrada en la canción? } \\
\text { ¿Qué tipo de relación se establece entre } \\
\text { ellos? } \\
\text { Respecto a este tipo de relación, ¿se } \\
\text { observa diferencia entre culturas? ¿De } \\
\text { qué tipo? }\end{array}$ \\
\hline
\end{tabular}

Conforme las respuestas de los estudiantes y su competencia metalingüística, el profesor puede señalar que, en algunas regiones de Colombia, se realizan las dos formas de tratamiento para contextos de intimidad, como en la canción de Juanes - en el sentido apuntado en el estudio lingüístico de Calderón Campos (2010, p. 230): "en la región voseante colombiana "hay frecuentes alternancias vos/tú/usted en el mismo acto comunicativo y con el mismo interlocutor". Sin embargo, es importante destacar que, en la variación túlvos en géneros textuales como poesía y canción, aspectos como el ritmo y la rima pueden influenciar en las elecciones lingüísticas, tal como en el uso de los pronombres de tratamiento.

Pasando a la canción puertorriqueña, se verifica la presencia de las formas tú y usted en el tratamiento de segunda persona singular, tal como se ejemplifica a partir de los datos de (10) a (13):

10. "El amor que tú me dabas no valió nada"

11. "Como tú lloraste yo también lloré, no te sorprendas"

12. "Yo sé que yo no fui un santo pero usted no fue muy santa"

13. "No reclames si usted no lo hizo bien".

En (10), se observa el pronombre tú junto a la forma conjugada en segunda persona singular del verbo dar, en pretérito imperfecto; en (11), se encuentra el pronombre tú de forma explícita, acompañado de los verbos llorar y sorprender, conjugados en segunda persona singular, del pretérito indefinido e imperativo negativo. Interesa destacar la presencia de la forma usted en los 
datos ilustrados en (12) y en (13). En (12) se observa la correspondencia verbal expresa en la morfología del verbo "ir", conjugado en tercera persona singular del pretérito indefinido - "usted fue". En (13), por otro lado, llama la atención la ausencia de paralelismo verbo-pronominal, puesto que el verbo "reclamar" se presenta conjugado en segunda persona singular del imperativo negativo; en el mismo dato, el emisor emplea el tratamiento usted, seguido del verbo "hacer", conjugado en tercera persona singular del pretérito indefinido. Se trata de un fenómeno que merece la investigación del profesor de modo a verificar la posible extensión del fenómeno.

Respecto a esa variación entre dos formas, es igualmente importante señalar la mayor frecuencia de la forma tú en la referida canción, como se observa en los versos a continuación.

15. "De que tú hablas y porque me reclamas si caimos en la tentación"

16. "Soy igual que tú"

17. "Deja el show, no me vengas con ese flow"

18. "Y ya sé que vas a llorar"

19. "Pero ni siquiera te atrevas a reclamar"s

Bajo la mirada cualitativa y discursiva sugerida en este estudio, llamamos la atención al uso de usted y sus formas verbales correspondientes en un contexto tuteante, en que se mantiene la misma relación entre los interlocutores. En atención a este fenómeno presente en la lengua en uso - aunque estemos tratando de un texto más planeado, como es la canción, no se puede ignorar su representatividad - , el profesor podrá debatir con sus alumnos la alternancia de pronombres de tratamiento en una misma interacción, a partir de los cuestionamientos presentados en el cuadro 4.

5 Estos datos pueden corroborar la hipótesis sexista apuntada por Carricaburo (1997), al afirmar que los hombres tienden a tutear más a las mujeres que a otros hombres. 
Cuadro 4. Datos y cuestiones para análisis didáctico

\begin{tabular}{|c|c|}
\hline Datos & Cuestiones para reflexión \\
\hline $\begin{array}{l}\text { 20. "Yo sé que yo no fui un santo pero } \\
\text { usted no fue muy santa" }\end{array}$ & $\begin{array}{l}\text { ¿Quiénes son los participantes de la } \\
\text { interacción ilustrada en la canción? }\end{array}$ \\
\hline $\begin{array}{l}\text { 21. "No reclames si usted no lo bizo bien, } \\
\text { bien" }\end{array}$ & $\begin{array}{l}\text { ¿Qué tipo de relación se establece entre } \\
\text { ellos? }\end{array}$ \\
\hline $\begin{array}{l}\text { 22. "Ya me di de cuenta que usted no me } \\
\text { conviene" }\end{array}$ & $\begin{array}{l}\text { ¿Cuáles pronombres de tratamiento está } \\
\text { presente en la interacción ilustrada? }\end{array}$ \\
\hline \multirow{3}{*}{$\begin{array}{l}\text { 23. "Aguante muchas pitchaeras, muchos } \\
\text { nebuleos". }\end{array}$} & ¿A qué atribuyes el cambio de tratamiento? \\
\hline & $\begin{array}{l}\text { ¿Crees que hay razones para que el } \\
\text { hablante cambie la forma tú por la forma } \\
\text { usted? ¿Cuáles? }\end{array}$ \\
\hline & $\begin{array}{l}\text { ¿En tu lengua materna, también se } \\
\text { observa esta alternancia? ¿Por razones } \\
\text { semejantes o diferentes? }\end{array}$ \\
\hline
\end{tabular}

Tras este momento de práctica metalingüística, se espera que los estudiantes observen que el uso de usted en este contexto no es resultante de una situación de formalidad y/o distanciamiento entre los interlocutores, sino más bien de un recurso estilístico capaz de expresar el enfado del hablante frente a la traición de su compañera. Consecuentemente, el profesor puede junto a sus alumnos reflexionar sobre la clásica y simplificada división bipartida tú; vos/informalidad y usted/formalidad, presentada a menudo en el ámbito pedagógico, pero que no comprende la diversidad de la lengua, en términos geográficos y estilísticos, fundamentalmente.

Debatir sobre estas diferencias en el uso de los pronombres de tratamiento en Colombia y Puerto Rico es una forma de aproximar a los estudiantes de las variedades lingüísticas y de la cultura de estos países (conforme el abordaje que se dé) con la tentativa de deshacer prejuicios o estereotipos. Esta idea es coherente con lo que afirma Kraviski (2007) sobre la necesidad de abarcar las variantes lingüísticas en el componente cultural, pues el modo como se habla en determinada región también forma parte de su cultura. Además, como eva- 
luación de esta actividad, el profesor puede verificar si los alumnos comprendieron las diferencias en el uso de los tratamientos en los países estudiados y si son capaces de distinguir el registro adecuado para cada país, según el contexto de la interacción.

Otra sugerencia didáctica pertinente es pedir a los estudiantes que intenten completar las canciones con los pronombres complemento adecuados conforme su propio juicio a partir de las relaciones interpersonales observadas. Es posible que las completen en atención a la norma estándar presentada en libros didácticos: $t u ́$, en contextos de informalidad; usted, en contextos de formalidad. En esta propuesta, el profesor, al pasar la canción, puede mostrar los diferentes usos de los pronombres en Colombia y Puerto Rico, fomentando la reflexión acerca de la diversidad lingüística y cultural del español, a partir de la discusión de la norma social practicada en estas sociedades.

\section{Consideraciones finales}

Con este artículo, se buscó reflexionar sobre la variación en el uso de los pronombres de tratamiento de segunda persona singular desde una mirada didáctico-pedagógica. Aunque el uso de las canciones en clases de lengua extranjera no sea tema novedoso, se propone en este trabajo el uso de este género textual en actividades que contemplan, más allá de la comprensión auditiva, la reflexión sobre el fenómeno lingüístico específico y sobre las relaciones entre lengua, sociedad y cultura.

Asimismo, a través de esta propuesta de actividad, también buscamos fomentar la reflexión sobre la variación lingüística, a fin de combatir prejuicios y estereotipos lingüísticos y/o culturales de alumnos brasileños que estudian lengua española, en atención a lo que establecen documentos oficiales, como OCN/EM (BRASIL, 2006) y PCN/EM (BRASIL, 2000). Presentar actividades didácticas con base en canciones atentamente seleccionadas - conforme el objetivo que se tenga - posibilita crear la conciencia de la pluralidad lingüística y cultural de la lengua española, lo que contribuye, además, para suplir lagunas de libros didácticos, que, por razones diversas, suelen presentar tratamiento desigual de las variedades hispanohablantes, destacando cierta variedad en detrimento a las diversas otras, conforme estudios de Oliveira (2014), Pontes (2009), Nascimento (2007), Kraviski (2007), Santos (2002) y Buguel (1998). 


\section{Referencias}

AYALA, Berenice Férez de. Um estudo sobre a prática pedagógica do professor de lingua espanhola, 2004. 112f. Tesis de maestría. Itajaí: UNIVALI. 2004.

BRASIL, Ministério da Educação. Parâmetros Curriculares Nacionais para o ensino Médio. Parte II Linguagens, Códigos e suas tecnologias. Brasília: Secretaria de Educação Média e Tecnológica, 2000. Disponible en: http://portal.mec. gov.br/seb/arquivos/pdf/14_24.pdf. Accedido en: 14 jun. 2013.

- Orientaçóes Curriculares Nacionais para o Ensino Médio Linguagens, Códigos e suas tecnologias. Brasília: Secretaria de Educação Média e Tecnológica, 2006. Disponible en: http://portal.mec.gov.br/seb/arquivos/pdf/book_volume_01_internet.pdf. Accedido en: 14 jun.2013.

. Lei 11.161. Disponible en: http://www.planalto.gov.br/ccivil_03/_ Ato2004-2006/2005/Lei/L11161.htm. Accedido en 14 jun. 2013.

BUGEL, Talia. O espanhol na cidade de São Paulo: Quem ensina qual variante a quem? Campinas, 1998. 137 f. Máster - Universidade Estadual de Campinas, Instituto de Estudos da Linguagem. 1998.

CALDERÓN CAMPOS, Miguel. Formas de tratamiento. ALEZA IZQUIERDO, Milagros; ENGUITA UTRILLA, José Ma. (Coord.). La lengua española en América: Normas y usos actuales. Universidad de Valencia, Valencia: 2010, p. 225-236.

CARRICABURO, Norma. Las fórmulas de tratamiento en el español actual. Cuadernos de Lengua Española. Madrid: Arco Libros, S.A., 1997.

COAN, Márluce; PONTES, Valdecy. Variedades linguísticas e ensino de espanhol no Brasil. Revista Trama, Vol. 9, no 18: 179-191, 2o semestre, 2013.

FERREIRA, Martins. Como usar a música na sala de aula. $8^{a}$. ed. São Paulo: Contexto, 2012.

GERALDI, J. W. O texto na sala de aula. Cascavel: Assoeste, 1991.

KRAVISKI, Elvys Regina Andretta. Estereótipos culturais: o ensino de espanhol e o uso da variante argentina em sala de aula, 2007. 132f. Curitiba: Universidade Federal do Paraná. 2007.

LABOV, W. Where does the Linguistic variable stop. A response to Beatriz Lavandera. Sociolinguistic Working Paper, 44. Texas, 1978. 
LEDEZMA, Fanny del Carmen Dalis. Recursos didácticos en la enseñanza de idiomas extranjeros: un estudio sobre el uso de la música en el aula de ELE en Noruega, 2007. 148 f. Tesis de maestría del Departamento de Lenguas Extranjeras Español y Estudios latinoamericanos de la Universidad de Bergen, Bergen, Noruega. 2007.

MATOS E SILVA, Rosa Virgínia. Contradiçôes no ensino do português. São Paulo: Contexto, 1995.

MOLLICA, Maria Cecília; BRAGA, Maria Luiza (Orgs.). Introdução à Sociolinguistica: o tratamento da variação. 3ed. São Paulo: Contexto, 2007.

MORENO FERNÁNDEZ, Francisco. Qué español enseñar. Cuadernos de Didáctica del español/LE. Madrid: Arco/Libros, S.L, 2000. bros, 2010

. Las variedades de la lengua española y su enseñanza. Madrid: Arcoli-

NASCIMENTO, Erivaldo Pereira. Prestígio lingüistico no ensino de espanhol como lingua estrangeira: o caso dos Pronombres Personales Sujeto. Studia Diversa, CCAE - UFPE, Vol. 1, No 1, 2007. Disponible en: http://www.ccae.ufpb.br/ public/studia_arquivos/arquivos_01/erivaldo_01.pdf. Accedido en: 20 nov. 2013.

OLIVEIRA, L. C. de. O multifuncional pretérito perfeito composto espanhol em materiais didáticos. Calidoscópio, Vol. 12, n. 1: 83-93, 2014.

PEREIRA, L. L. de O. La enseñanza de la variación lingüistica en las formas de tratamiento en español a través de músicas: propuestas de actividad, 2014. $74 \mathrm{f}$. Monografia. Fortaleza: Universidade Federal do Ceará. 2014.

PONTES, Valdecy de Oliveira. As categorias verbais tempo, aspecto e modalidade em livros didáticos de língua portuguesa e de lingua espanhola: análise contrastiva, 2009. 89f. Monografia de Especialização em Linguística Aplicada. Fortaleza: Faculdade Sete de Setembro. 2009.

SANTOS ASENSI, Javier. Música, maestro... Trabajando con música y canciones en el aula de español. Actas del VI Congreso Internacional de ASELE: Actuales tendencias en la enseñanza del español como lengua extranjera II, Rueda, M. y otros (Eds.). León, Universidad de León, 1996. p. 367-378.

SANTOS, Héladi Scutti. O papel de estereótipos e preconceitos na aprendizagem de línguas estrangeiras. Anales del II congreso brasileño de hispanistas, São Paulo. 2002. 
SILVA, Virgínia Cândido. A música popular brasileira: instrumento de compreensão das diferenças linguísticas. Aplicação didático-pedagógica das variaçôes presentes em letra-de-música de diferentes períodos, 2007. 152f. Dissertação (Mestrado em Letras) - Instituto de Letras, Universidade Estadual do Rio de Janeiro, Rio de Janeiro. 2007.

\title{
THE TEACHING OF "TÚ ", "VOS" AND "USTED" THROUGH SONGS: A SOCIOLINGUISTIC APPROACH
}

\begin{abstract}
We hereby present a didactic approach for the teaching of Castilian pronouns tú / vos / usted, based on songs from different Spanish-speaking regions. Our debate, focused on the pedagogical context, is based on the Labovian Sociolinguistic theoretical principles as well as on official documents addressing teaching subjects.
\end{abstract}

KEY WORDS: linguistic variation and change; secondperson pronouns; education.

Recebido em: 028/03/2015 Aprovado em: 26/09/2015 